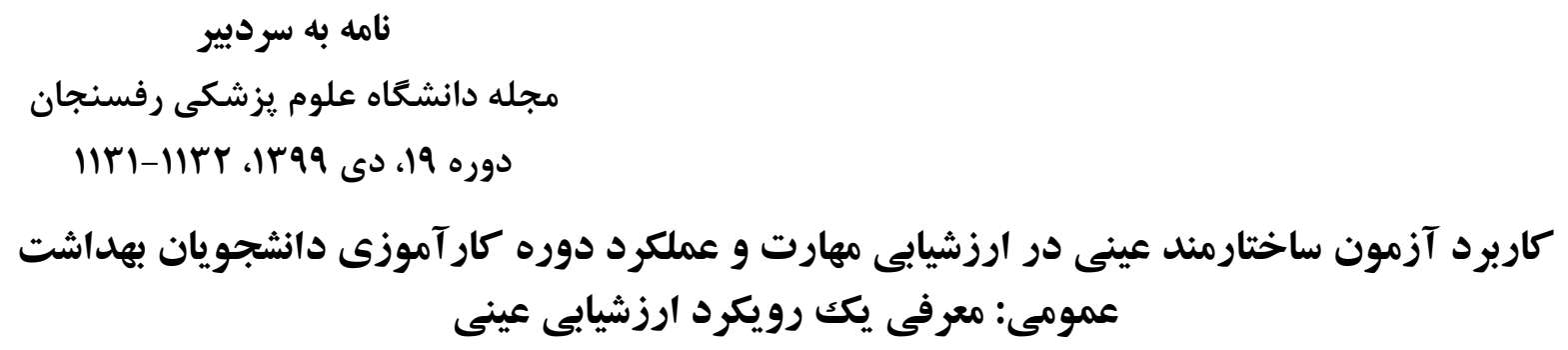

\title{
Application of Structured Objective Exam in Assessing Skills and Performance of Public Health Students' Internship: Introducing an Objective Evaluation Approach
}

مهدى عبدالكريمى '

\section{Abdolkarimi}

باردار، كودكان، سالمندان و همرجنين حفظ و ارتقاى سلامت

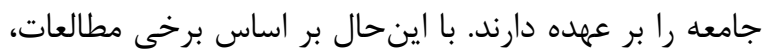

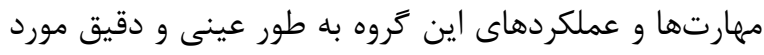

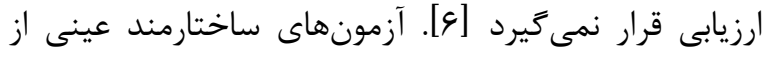

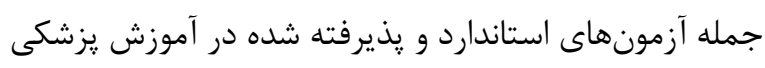

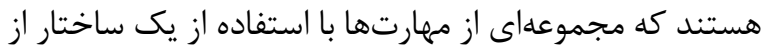

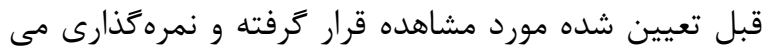

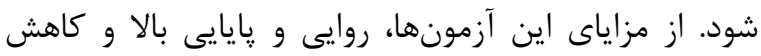

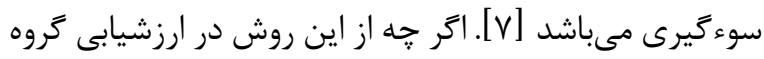

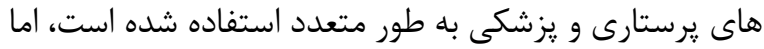
به ندرت در سنجش مهارتهاى ارائه كنندكان خدمات بلدات بهداشتى اوليه از اين آزمونها استفاده شده است.

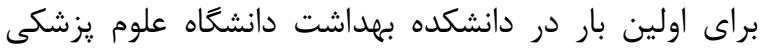
رفسنجان، جهت ارزيابى مهارتهاى اساسى فراگيران رشته بهداشت از آزمون ساختارمند عينى بررسى عملكرد و مهارت هيارت Objective Structured Clinical/ (OSCE/OSPE) Practical Examination 19 إ، جهت ارزيابى مهارتهاى پايان دوره كارشناسى \begin{abstract}
مقلمهه
مراقبتهاى بهداشتى اوليه (Primary Health Care) اساس بزرگترين سيستمهاى ارائه خدمات سلامت را تشكيل مى بـ

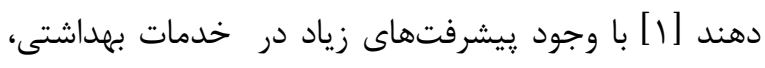
كيفيت خدمات بهداشتى اوليه همرجنان مورد ترديد قرار دارد. بهبود كيفيت آموزش كنندكان خدمات سلامت مىتواند در ارتقاى كيفيت خدمات تأثير كذار باشد [ب]. يكى از عوامل تعيين كننده آموزش، كيفيت ارزشيابى دانشآموختكان است، به صورتى كه اگر ارزشيابى، محدود به سطوح پايين حيطه

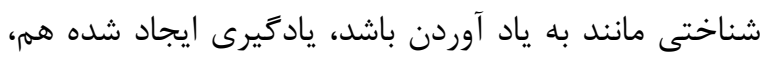

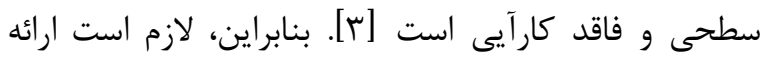
كنندكان خدمات بهداشتى اوليه، با استفاده از روشهاى عينى

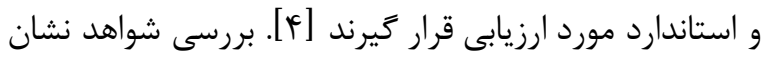

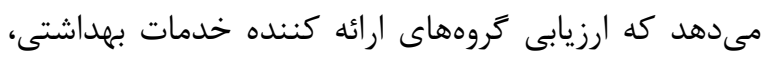
بيشتر با استفاده از روشهاى تئورى صورت كرفته است [هاى]. مراقبين سلامت، به عنوان سطح اول ارائه خدمات بهداشتى

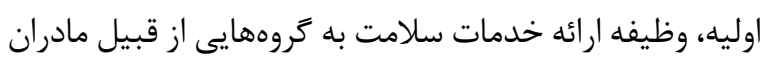

$$
\text { 1-(نويسنده مسئول) استاديار، كروه آموزش بهداشت و ارتقاء سلامت، دانشكده بهداشت، دانشكاه علوم بزشكى رفسنجان، رفسنجان،ايران }
$$

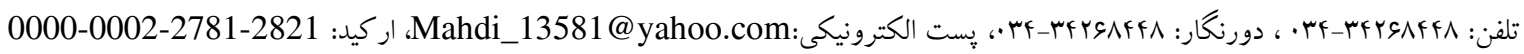




$$
\begin{aligned}
& \text { در مواجهه با يك مددجوى آموزش ديده شده مورد ارزيابى }
\end{aligned}
$$

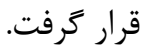

$$
\begin{aligned}
& \text { اكر جه جازخورد اكثريت دانشجويان و مربيان، در مورد } \\
& \text { توانايى اين آزمون در سنجش مهارتهاى اساسى در ارائه } \\
& \text { خدمات PHC مثبت بود، اما با توجه به جديد بودن، اين آزمون } \\
& \text { با محدوديتهايى از جمله استرس دانشجويان و عدم امكان } \\
& \text { سنجش همه مهارتهاى ضرورى همراه بود. بنابراين پيشنهاد } \\
& \text { مى گردد در برنامه درسى طراحى شده و در حال اجراى } \\
& \text { فراگيران ارائه كننده خدمات سلامت جامعه، ارزيابى دقيق } \\
& \text { نحوه ارائه خدمات سلامت مورد توجه بيشترى قرار گيرد. } \\
& \text { اميد است با طراحى آزمونهاى دقيقتر و استاندارد، كه } \\
& \text { مى تواند در نحوه آموزش بالينى اين گروهها هم تحول مثبتى } \\
& \text { ايجاد كند، شاهد ارتقاء خدمات سلامت جامعه باشيم. }
\end{aligned}
$$

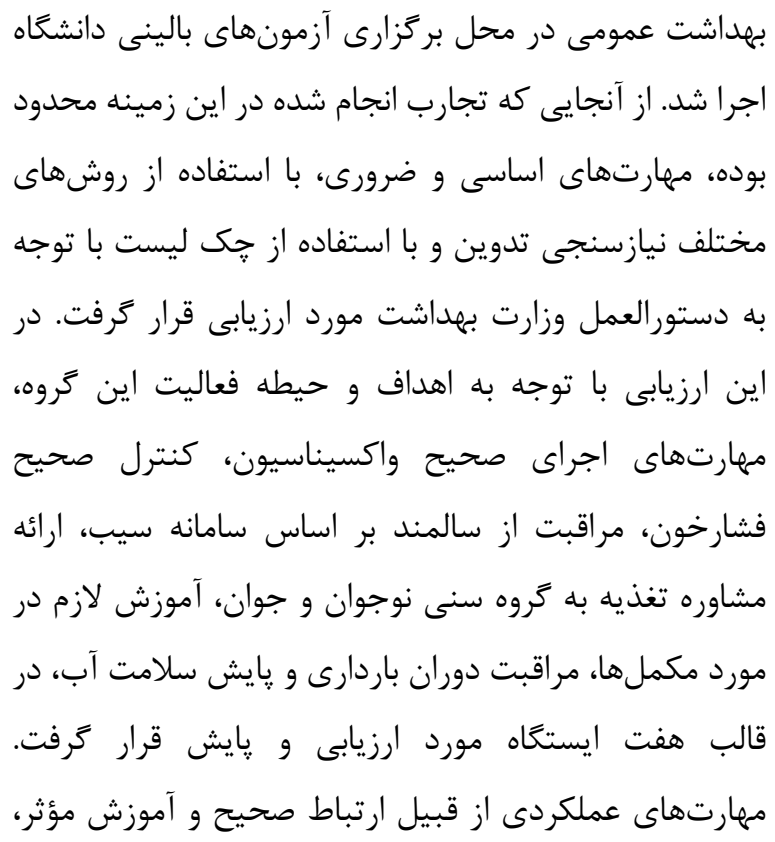

\section{References}

[1] Sellera PE, Pedebos LA, Harzheim E, Medeiros OL, Ramos LG, Martins C, et al. Monitoring and evaluation of Primary Health Care attributes at the national level: new challenges. Cien Saude Colet 2020; 25 (4): 1401 12.

[2] Li X, Krumholz HM, Yip W, Cheng KK, De Maeseneer J, Meng Q, et al. Quality of primary health care in China: challenges and recommendations. The Lancet 2020; 395(10239): 1802-12.

[3] Miguel EM, Ruiz MD, Blas EG, Perea CM. Competency assessment impact in quality of learning: Nursing degree learners and teachers perception. Enfermeria Global 2018; (50): 420-33.

[4] Tabrizi JS. Objective Structured Field Examination (OSFE). Iran J Med Sci 2012; 11 (8): 976-8.
[5] Wadde S, Deshpande R, Madole M, Pathan III F. Assessment of III MBBS students using OSPE/OSCE in community medicine: Teachers' and students' perceptions. Sch J App Med Sci 2013; 1(4): 348-53.

[6] Parvizrad P, Rezaei S. Clerkship of Public Health from Students \& Educational groups' Perspective: A Qualitative Research. J Med Educ Dev 2014; 7 (13): 16-27.

[7] Selim AA, Ramadan FH, El-Gueneidy MM, Gaafer MM. Using Objective Structured Clinical Examination (OSCE) in undergraduate psychiatric nursing education: Is it reliable and valid? Nurs Educ Today 2012; 32: 283-8. 